OnLine Journal of Biological Sciences 13 (2): 41-49, 2013

ISSN: 1608-4217

(C) 2013 Hassina and Ahmed, This open access article is distributed under a Creative Commons Attribution

(CC-BY) 3.0 license

doi:10.3844/ojbssp.2013.41.49 Published Online 13 (2) 2013 (http://www.thescipub.com/ojbs.toc)

\title{
ISOLATION AND CHARACTERIZATION OF HELICOBACTER PYLORI STRAINS FROM GASTRIC BIOPSIES OF ALGERIAN PATIENTS
}

\author{
${ }^{1}$ Guetarni Hassina and ${ }^{2}$ Bensoltane Ahmed \\ ${ }^{1}$ Department of Biology, Faculty of Natural Sciences, Life and Earth Sciences, \\ University of Khemis Miliana, 44225, Ain Defla, Algeria \\ ${ }^{2}$ Department of Biology, Faculty of Natural Sciences and Life, Laboratory of Biotoxicology Experimental, \\ Biodepollution and Phytoremediation, University of Oran Es-Senia, 31000, Algeria
}

Received 2013-06-02, Revised 2013-06-15; Accepted 2013-06-19

\begin{abstract}
The objective of this study is to isolate and characterize strains Helicobacetr pylori from gastric biopsies by upper gastrointestinal endoscopy. After a rapid urease test, two Helicobacter pylori strains isolated from four patients on blood agar. After extraction of DNA from these strains from homogenates of gastric biopsies, quantification by real-time PCR was performed to determine Helicobacter pylori on the one hand and sensitivity to clarithromycin species. Melting curve analyzes showed that these two strains are sensitive to the antibiotic.
\end{abstract}

Keywords: Helicobacter pylori, Culture, Urease, Real-Time PCR, Clarithromycin

\section{INTRODUCTION}

In 1875 the German Scientists found the presence of spiral bacteria in human stomachs. They abandoned the research because they did not arrive at the farm. It took until 1982 for two Australian researchers (Warren and Marshall, 1984) in research consisting have been able to isolate and cultivate organisms from human stomachs (Kidd and Modlin, 1998). H. pylori is a pathogenic bacterium that can colonize the gastric mucosa and not if there is no gastric metaplasia infects the duodenum (Bigard, 2004). Following infection with $H$. pylori, the main steps of the process of carcinogenesis are: Chronic active gastritis, gastric atrophy, intestinal metaplasia, dysplasia and gastric cancer (Kuipers, 1999; Peek and Blaser, 2002). Techniques for the diagnosis of $H$ pylori infection include genetic methods, microbiological, pathological, immunological and those based on the detection of bacterial urease activity. These methods are either invasive requiring endoscopy with biopsy or non-invasive (Korwin and Lozniewski, 2000). For this, the objectives of this study is to isolate strains of Helicobacter pylori from gastric biopsies of patients who suffered an upper endoscopy.

\section{MATERIALS AND METHODS}

\subsection{Collection of Gastric Biopsies}

Patients who underwent upper gastrointestinal endoscopy to collect gastric antrum biopsies, including age and sex of the patients are presented in Table 1. A biopsy specimen is placed in the urea-indole broth for the presence of urease, two fragments in physiological saline for isolation of $\mathrm{H}$. pylori and a fragment in $4 \%$ formalin for histological examination-pathological and cytological.

Corresponding Author: Guetarni Hassina, Department of Biology, Faculty of Natural Sciences and Earth Sciences, University of KhemisMiliana, 44225, AinDefla, Algeria 
Table 1. Sex and age of the patients underwent upper gastrointestinal endoscopy

\begin{tabular}{lllllll}
\hline Patient & 1 & 2 & 3 & 4 & 5 & 6 \\
\hline Sex & Man & Man & Woman & Woman & Woman & Woman \\
Age (year) & 19 & 43 & 64 & 35 & 62 & 59 \\
\hline
\end{tabular}

\subsection{The Rapid Urease Test}

A fragment is placed in a tube containing urea indole to detect urease activity which shows the presence of the bacteria in the biopsy (Cassel-Beraud et al., 1996). The positive result is interpreted by the color change of urea-indole from orange to pink or red after incubation at $37^{\circ} \mathrm{C}$ for $24 \mathrm{~h}$

\subsection{Seeding and Characterization of Helicobacter pylori}

This part is designed to isolate and characterize strains of Helicobacter pylori, responsible for peptic ulcer disease from gastric biopsies. Stages of seed strains of $H$. pylori were mentioned by the SFM (2010).

\subsection{Grinding Biopsies}

Grinding allows the dispersion of bacteria and release of mucus cells, including three $1.5 \mathrm{~mL}$ PCR tubes are labeled: One is filled with $0.25 \mathrm{~mL}$ of the ground, one is empty (for PCR) and the other contains the remaining homogenate. Then $1 \mathrm{~mL}$ broth meat liver glucose (Bio-Rad) is put into the grinder (Kontes or Wheaton) and biopsies are crushed. It must contain a homogeneous solution without cell clusters. In order to increase the chances of culture and prevent obstruction of the tips in the step of DNA extraction.

\subsection{Gram Stain of Gastric Biopsy}

The Gram stain is a preliminary step used to differentiate Gram positive and Gram negative bacteria. Biopsies are spread as a smear on a glass slide (make sure the mucus has been on the slide) and stained by Gram's method in a PLC-CYTOCENTRIFUGE SlaideStainer (Wescor). This method allows to identify H. pylori in the surface of the mucosal epithelium of gastric biopsies.

\subsection{Seeding for the Stomach for Helicobacter pylori Biopsies}

Culture: Two types of agar were used: Pylori Agar (Biomerieux, France) and Agar house for culture of Helicobacter pylori, 4 drops of crushed are deposited on the surface of two plates. Then the plates are placed in the bag GENbagAnaer (Biomerieux, France) (two Petri dishes per bag) in the presence of a packet generator microaerophilic atmosphere (GENbagMicroaer, Biomerieux). Noting the bag GENbag the date of opening the bag (7 days after seeding). Finally, the bag is incubated in an oven at $37^{\circ} \mathrm{C}$ (Telewig CCH01-00900-R05-291-333).

\subsection{Identification of $\mathrm{H}$. pylori}

From Cassel-Beraud et al. (1996), the identification of $H$. pylori was based on its morphological characteristics: intense urease presence of an oxidase and a catalase: Small round colonies, bulging and glossy, its microscopic examination and its essential biochemical characters long.

\subsection{Real-Time PCR}

Quantitative real-time PCR based on the ability to track over time the process of PCR using fluorescence. Fluorescence data are collected at each PCR cycle and represent the amount of product amplified to that point (Elyse, 2002). In our study, the real-time PCR is used to detect both $H$. pylori in gastric biopsies and sensitivity to clarithromycin. This antibiotic is indeed one of the first treatment of infection with H. pylori and the success of the treatment is partly dependent on the sensitivity of the bacterium. The extraction of DNA from $H$. pylori has been made in the PLC easyMAGNucliSens $₫(00982$, Biomerieux, France). To prepare Master Mix, $10 \mu \mathrm{L}$ tube containing LightCycler Fast-Start enzyme in the tube LightCyclerFastStart Reaction Mix SYBR Green I was pipetted The LightCyclerFastStart DNA Master SYBR Green I got (Roche Diagnostics, Applied Science) containing Fast Start Taq DNA polymerase, reaction buffer, dye Syber Green and dNTP mix (with dUTP instead of dTTP). In a box Centrifuge Adapters 1909312 Light Cycler (Roche, Germany) were placed in tubes Mix.We used for preparation a sense primers HPYS (416018-3/4 ;Eurofins mwg/Operon), 5'-AGG-TTA-AGAGGA-TGC-GTC-AGT-C-3, nucleotides 1931-1952') and antisense HPYAS (41-6018-4/4; Eurofins mwg/Operon), 5'-CGC-ATG-ATA-TTC-CCA-TTA-GCA-GT-3', nucleotides 2197-2175). The extraction of DNA from $H$. pylori has been made in the PLC easyMAGNucliSens ${ }^{\circledR}$ (00982, Biomerieux, France). The amplified product was detected with both probes: the detection probe HP-LCR (41-6018-1/4; Eurofinsmwg/operon), labeled 5' with LCRed 640 and phosphorylated at the 3' (5'- GGC-AAG- 
CAG-GAA-AGA-CC-3', nucleotides 2504-2520) and HP-FLU anchor probe (24-66592/2; Eurofinsmwg/Operon) fluorescein-labeled 3' (2466592/2, 5'-AGT-TGT-GGA-GGT-GAA-AAT-TCCTCC-TAC-CC-3', nucleotides 2473-2501). For each sample to be studied, the mix should contain $8.4 \mu \mathrm{L}$ of $\mathrm{H} 2 \mathrm{O}, 1 \mu \mathrm{L}$ of HPY-S $(10 \mu \mathrm{M}) 1 \mu \mathrm{L}$ HP-LCR $(10 \mu \mathrm{M}), 1 \mu \mathrm{L}$ of HP-FLU $(10 \mu \mathrm{M}), 1 \mu \mathrm{L}$ of HPY-AS $(10 \mu \mathrm{M}), 2 \mu \mathrm{L}$ of master mix and $1.6 \mathrm{MgCl} 2(25 \mathrm{mM})$. In this type of two PCR positive controls were used: Quinet for the wildtype strains and Alves for strains with mutations in 2143 and $\mathrm{H} 2 \mathrm{O}$ for the negative control. After adding $4 \mu \mathrm{L}$ DNA extracted to $16 \mu \mathrm{L}$ of prepared mix. The previously prepared microtubes were centrifuged and placed in the thermal cycler Light Cycler 2.0 (Roche, Germany). The basic steps of DNA detection in real-time PCR on the LightCycler system are as follows: preincubation at $95^{\circ} \mathrm{C} / 10 \mathrm{~min}$ involves activation of FastStart DNA polymerase and denaturation of double-stranded DNA (50cycles with a temperature transition rate of $20^{\circ} \mathrm{C} / \mathrm{s}$ ). It takes place at a temperature of $95^{\circ} \mathrm{C}$ for $0 \mathrm{~S}$. The second period is at a temperature of $60^{\circ} \mathrm{C}$ for $10 \mathrm{~s}$, said temperature of primer annealing. For hybridization HPFLU probe emits green light when excited by the device. Its emission spectrum overlaps the excitation spectrum of an acceptor fluorophore located at the 5' end of the second probe HP-LCR labeled 5' with LC-Red 640 and phosphorylated at the $3^{\prime}$. Thereof is blocked at the $3^{\prime}$ to prevent extension from its end. The excitation of fluorescent donor (fluorescein) is transmitted by FRET (Fluorescence Resonance Energy Transfer) to fluorescent acceptor which emits red light. The two probes are hybridized to "tumble" of the target sequence during the hybridization step. The fluorescence is reversible and will help to generate melting curves. Decrease in temperature makes hydrogen bonds from reforming and therefore the complementary strands to hybridize. The third stage is carried out at a temperature of $72^{\circ} \mathrm{C}$ for $17 \mathrm{~s}$, said stretching temperature. At this temperature, the FastStartTaq DNA polymerase binds to single-stranded DNA replication initiated and catalysis using dNTPs present in the reaction mixture. After amplification a melting step was carried out: Denaturation at $95^{\circ} \mathrm{C}$ for $0 \mathrm{sec}$, cooling to $45^{\circ} \mathrm{C}$ for $30 \mathrm{sec}$ (with a temperature transition rate of $20^{\circ} \mathrm{C} \mathrm{sec}{ }^{-1}$ ) and a slow increase in temperature at $85^{\circ} \mathrm{C}$ at a rate of $0.1^{\circ} \mathrm{C} \mathrm{sec}{ }^{-1}$, with continuous acquisition of fluorescence decay.

\section{RESULTS}

\subsection{The Rapid Urease Test}

The urease test is based on the abundant production of urease by $H$. pylori. The results show a pink color of Urea -indole containing biopsies of only four patients (Fig. 1).

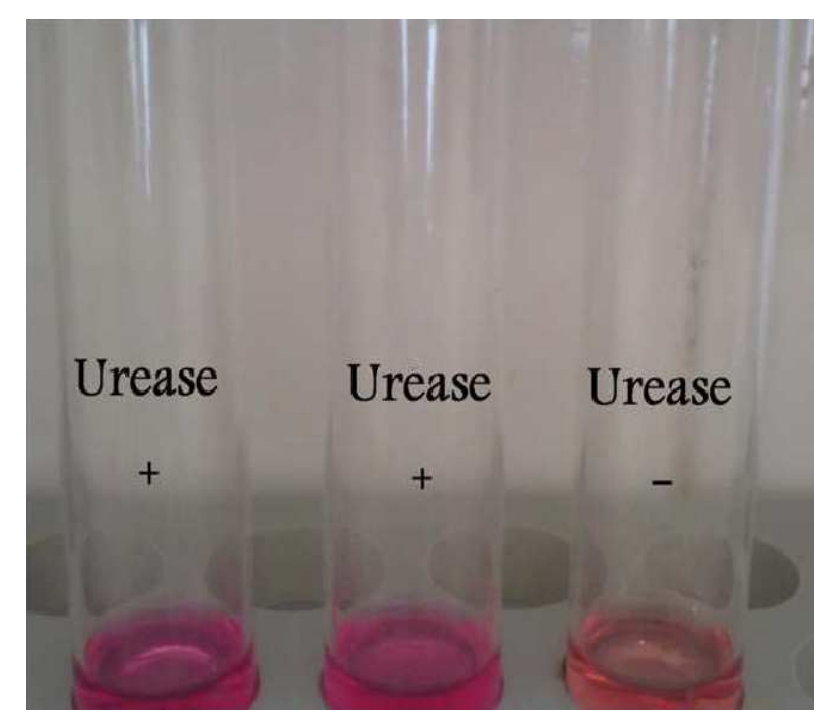

Fig. 1. Rapid urease test 


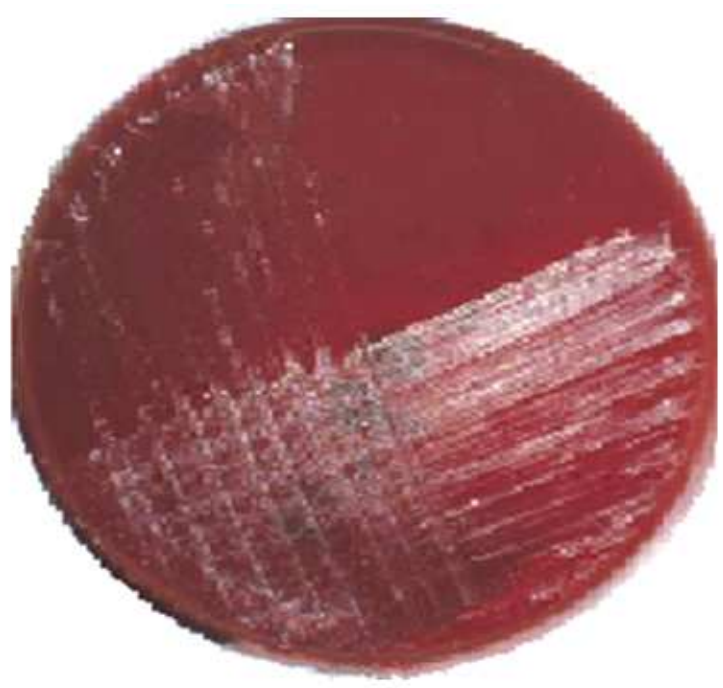

Fig. 2. Appearance of colonies of Helicobacter pylori on house agar after incubation at $37^{\circ} \mathrm{C}$ for 7 days and under microaerophilic atmosphere

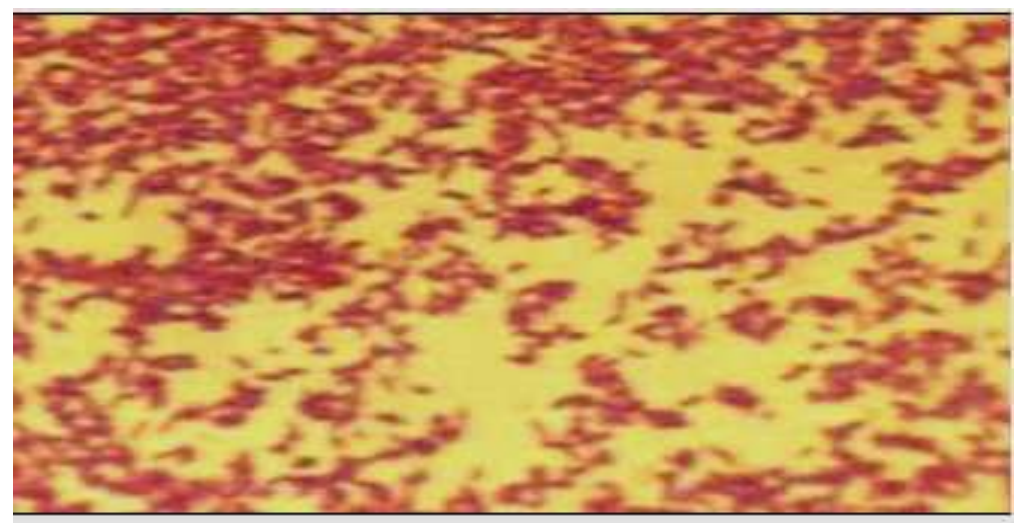

Fig. 3. Appearance of Helicobacter pylori cells after culture under an optical microscope after Gram staining (1000)

\subsection{Seeding for the Stomach for Helicobacter pylori Biopsies}

After 7 days of incubation at $37^{\circ} \mathrm{C}$ in a microaerophilic atmosphere, fine colonies, transparent gray and shiny, appear in the agar house, these cultural characteristics correspond to Helicobacter pylori. The colonies were spread on agar and delivery incubated to obtain a bacterial lawn on the agar (Fig. 2).

The microscopic examination of a smear prepared from suspect colonies by setting the drop of the bacterial suspension in the flame and then the smear is stained by Gram's method has allowed to observe fine cells pink proving membership the Gram negative.
These cells are much more in the form of bacillus. These are the morphological characters of $H$. pylori cells under an optical microscope (Fig. 3). Two strains of $H$. pylori isolated on agar House, showed the presence of a very active urease, oxidase and catalase.

\subsection{Microscopic Observation of Smears from Gastric Biopsies}

Microscopic observation to immersion after Gram staining showed the presence of curved Gram-negative bacteria in gastric biopsies. These bacteria belong to Helicobacter pylori (Fig. 4). 


\subsection{Quantification of Helicobacter pylori in Gastric Biopsies by Real-Time PCR}

Fluorescence datafor each PCR cycle are collected and expressed by curves with the Light Cycler Software Version 4.0.5.415 (Roche). Figure 5 shows DNA amplification curves, these curves express the fluorescence emitted as a function of number of cycles, which is obtained as three amplification curves (blue curve for the positive control used in determining the presence of strains of $H$. pylori sensitive to clarithromycin), pink curve indicates the presence of $H$. pylori in biopsy 1 and red curve also indicates the presence of $H$. pylori in the biopsy 3 . We noticed the presence of three phases for each amplification curve:

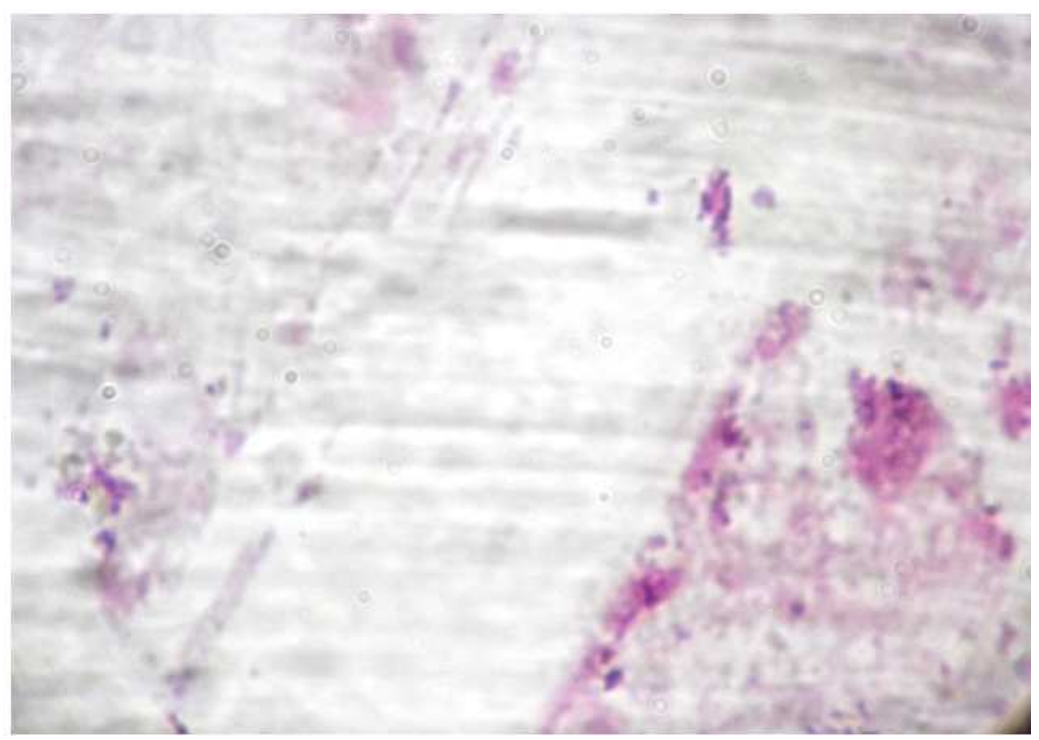

Fig. 4. Microscopic observation of smears prepared from gastric biopsy and colored by Gram's method (1000)
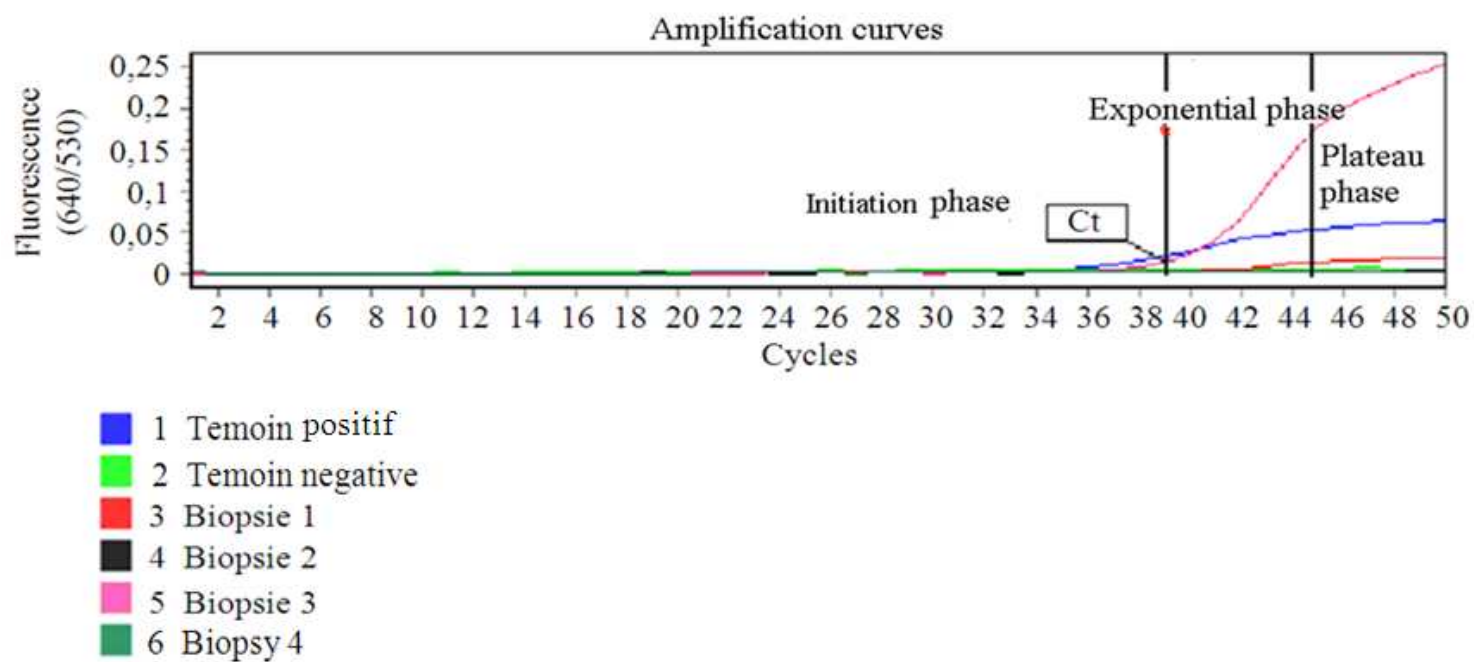

Fig. 5. Curves of DNA amplification which expresses the amount of amplicons (Fluorescence (640/530) issued based on the number of cycles): positive control (blue curve), negative control (light green curve), biopsy 1 (red curve), biopsy 2 (black curve), biopsy 3 (pink curve) and biopsy 4 (dark green curve) 


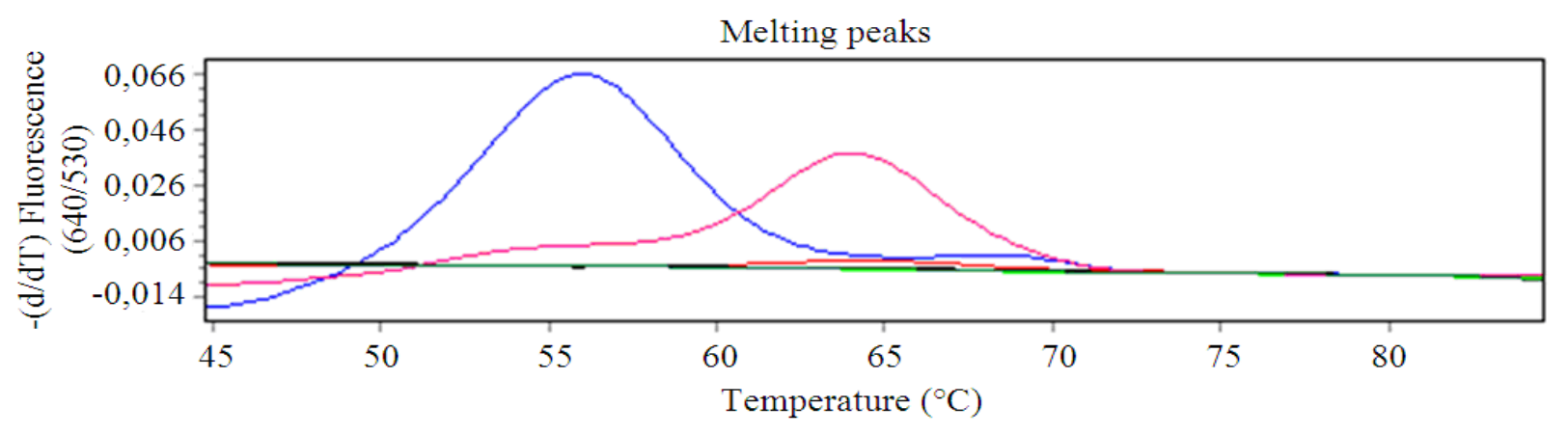

1 Temoin positif

2 Temoin negatif

3 Biopsie 1

4 Biopsie 2

5 Biopsie 3

6 Biopsie 4

Fig. 6. The melting curves: primary derived giving the Tm to determine the wildtype and mutant strains. The melting curve of $H$. pylori wildtype strains of biopsy 1 (red curve) $(\mathrm{Tm}=64.48)$ and biopsy 3 (pink curve) $(\mathrm{Tm}=63.913)$.

Table 2. Results of the qualitative detection

\begin{tabular}{lllll}
\hline & & & \multicolumn{2}{l}{ Results } \\
Position & Name & Type & CP & Score \\
\hline 1 & Temoin positif & Positive control & 35,67 & 5,00 \\
2 & Temoin negattif & Negative control & & $-2,91$ \\
3 & Biopsie 1 & Unknown & 39,29 & 5,00 \\
4 & Biopsie 2 & Unknown & & $-5,00$ \\
5 & Biopsie 3 & Unknown & 38,95 & 5,00 \\
6 & Biopsie 4 & Unknown & & $-3,99$ \\
\hline
\end{tabular}

Table 3. Tm, area and $\mathrm{L}$ of each peak

\begin{tabular}{|c|c|c|c|c|c|}
\hline \multirow[b]{2}{*}{ Position } & \multirow[b]{2}{*}{ Name of sample } & \multicolumn{4}{|l|}{ Peak } \\
\hline & & $\mathrm{Tm}$ & Area & Width & Length \\
\hline 1 & Temoin positif & 55,96 & 0,32 & 1,40 & 0,07 \\
\hline 2 & Temoin negatif & & & & \\
\hline 3 & Biopsie 1 & 64,48 & 0,03 & 1,39 & 0,00 \\
\hline 4 & Biopsie 2 & & & & \\
\hline 5 & Biopsie 3 & 63,91 & 0,13 & 1,49 & 0,04 \\
\hline 6 & Biopsie 4 & & & & \\
\hline
\end{tabular}

- A phase in which the amount of amplified fragment is insufficient to generate a fluorescent signal, the initiation phase.

- A phase in which a fluorescent signal is detected. This indicates expresses exponential phase. At the beginning of the PCR reaction there are more matrix amplify why we recorded a low number of cycles to reach a point where the fluorescence emission signal is higher than the background noise. This is the cycle threshold (Threshold cycle, $\mathrm{Ct}$ or $\mathrm{Cp}$ ). Qualitative detection at $640 \mathrm{~nm}$ shows that the positive control has a number of Cycles (CP) equal to 35.67. While biopsies 1 and 3 gave a positive result and CP varies from 39.29 and 38.95, respectively (Table 2)

- A third phase was observed in the curves of DNA amplification is expressed by a decrease in the number of the components of the reaction, the plateau phase

To prove that the only desired product was amplified by PCR, a melting curve analysis was carried out after PCR (Fig. 6). Each peak represents a melting characteristic Melting Temperature (Tm) of a DNA product. The most important factors that determine the Tm of double-stranded DNA is the length of GC content in this fragment. According to Table 3, the positive control used in this PCR gives a dead Time (T) equal to 55.96. If samples give a $\mathrm{Tm}=64.5^{\circ} \mathrm{C}\left(+/-1^{\circ} \mathrm{C}\right), H$. pylori is sensitive to clarithromycin (wildtype), compared with the dead-time amplification curves of DNA of strains $H$. pylori, biopsy 1 has a Tm equal to 64.48 and biopsy 3 has a Tm equal to 63.91. The results show the presence of $H$. pylori in only two biopsies taken from patients with acute and chronic gastritis. 
These strains are sensitive to clarithromycin. The latter expresses the possibility of treating $H$. pylori with clarithromycin which is clinically useful in the treatment of $H$. pylori by this antibiotic.

\section{DISCUSSION}

H. pylori is the pathogen that infects humans, it is estimated $50 \%$ of the world population. It is a common cause of ulcer dyspepsia and peptic potentially curable (Malfertheiner et al., 2012). The diagnosis of infection with $H$. pylori is most often from the antral and fundic biopsies taken during endoscopy by the gastroenterologist. Various tests are available, such as: A histological examination of the biopsies to detect the presence of $H$. pylori by microscopic examination, culturing bacteria from biopsies may also be performed; molecular testing gene amplification for the rapid detection of $H$. pylori and determination of susceptibility to clarithromycin (Zine-Charafe, 2007). For this we proceeded to isolate and characterize strains of Helicobacter pylori from gastric biopsies by upper endoscopy of age and patients of different sex, the urease test was positive for four of the six patients. After microscopic examination of smears prepared from gastric biopsies, culture homogenates of biopsies was performed on Muller Hinton agar supplemented with blood and two antibiotics pylori agar (bioMerieux) we observed small transparent colonies after incubation at $37^{\circ} \mathrm{C}$ for 7 days in Muller Hinton agar. These results show the possibility of $H$. pylori isolate this agar and the presence of this bacterium in both sexes. According Faik and Raiss (1998), bacteriological examination which requires biopsies after Gram staining, Gram-negative bacilli are sought throughout the smear. Then the culture of biopsy ground is planted in two environments, one of which is selective and incubated at $37^{\circ} \mathrm{C}$ in a microaerophilic atmosphere allows the susceptibility. Studies Cassel-Beraud et al. (1996) carried out during a period of 8 months, including Helicobacter pylori infection was investigated in 140 patients with upper gastrointestinal symptoms by conventional bacteriological methods (Gram stain, urea breath test, cultivation ) led to the identification of this bacterium from biopsy specimens of pyloric antrum mucosa. The prevalence of infection with $H$. pylori was $59 \%$. The prevalence did not appear differ depending on the age and sex but infection with $H$. pylori was significantly more frequently found in patients with active duodenal ulcer (30 cases out of 41) than in patients with normal endoscopy ( 21 of 47 cases) $(\mathrm{p}<0.02)$. This bacterium was isolated as viable in the stool of an infected person Gambia. The micoorganisme was grown on selective medium after concentration of fecal bacteria by centrifugation in a balanced blend with a microaerophilic gas buffer. Growth characteristics, microscopic appearances and the enzymatic activities of $H$. pylori were the same as those of a gastric-type isolate. Preparations derived from the new strain type proteins are antigenically similar and very similar electrophoretic profiles (including the two major protein bands of 62 and $26 \mathrm{kDa}$, corresponding to subunits of urease) (Thomas et al., 1992). In Algeria, Allem et al. (2007) have isolated a strain of $H$. pylori from gastric biopsy taken $2 \mathrm{~cm}$ from the pylorus of a patient with an ulcer. This biopsy is ground in $0.5 \mathrm{~mL}$ of nutrient broth and seeded in Petri dishes containing chocolate agar. They are put in a jar under microaerophilic atmosphere for a 5-day incubation at $37^{\circ} \mathrm{C}$. For enrichment, suspicious colonies are placed in a buffered glucose broth supplemented horse blood. The identification was made by evaluating the morphology of the bacteria, biochemical characters such as oxidase, urease, catalase and $\mathrm{H} 2 \mathrm{~S}$ production in TSI are also sought. After culturing, microscopic examination of a smear prepared from suspect colonies allowed us to observe for Gram-negative bacilli that can be Helicobacter pylori. These characters have been demonstrated by the work of Sobhani et al. (1995). Our results of the identification of the isolated strains of $H$. pylori strains have shown that these have on the one hand a very striking urease activity expressed by changing the color of urea-indole medium from orange to pink after $24 \mathrm{~h}$ incubation, on the other hand, an oxidase and a catalase. These biochemical characteristics were demonstrated by Monteiro (1995). Cassel-Beraud et al. (1996) found that after $60 \mathrm{~min}$, the change in color of the medium urea-indole from orange to red indicates the presence of bacteria in gastric biopsy. This bacterium has a very striking feature is the presence of a very strong urease activity, this property has been exploited for rapid diagnosis, the sensitivity of this method is between 71 and $91 \%$ at the 24th $\mathrm{h}$. The urease hydrolysis of this bacterium urea into ammonia and bicarbonate in order to neutralize the acidity of the stomach, a way to adhere to mucus cells (Sobhani et al., 1995). According Megraud and Lehours (2007) Cytochrome oxidase is present in all members of Epsilonproteobacteria. It is usually detected with special reagents on a disk or tape. Catalase is also present in all Helicobacter and most members Campylobacteraceae and is detected by the introduction of a loop of bacteria in a drop of hydrogen peroxide and the observation of a great production of bubbles. Urease 
is certainly the most important enzyme for identification. To survive in its ecological niche, $H$. pylori produces large amounts of this enzyme to buffer the acidic environment and creates a microenvironment. The realtime PCR detects multiple targets (the presence of $H$. pylori resistance to clarithromycin). The diagnostic performance are superior to those of histology and culture. It requires less stringent conditions of transport and culture. Gene amplification has excellent sensitivity and specificity for the diagnosis of infection with $H$. pylori and allows the determination of the main mutations involved in resistance to macrolides and fluoroquinolones (Lamarque et al., 2012). According Debongnie (1998), molecular biology is useful in the study of pathogenicity and immunization vis-à-vis Helicobacter pylori. The recent description of the genome of $H$. pylori causes molecular biology at the forefront in research on $H$. pylori. PCR is considered the most sensitive method for the detection of microorganisms. This would make the test particularly useful in the evaluation of eradication. Other indications include the detection of $H$. pylori outside the stomach, although $H$. pylori is present in small numbers among many other microorganisms causing false positive in other tests based on urease and culture. H. pylori has been found by PCR at the mouth and selles. La resistance to clarithromycin can be explained by a decrease in the affinity of the ribosome $H$. pylori to macrolides. Genetic support for this resistance was initially determined by (Versalovic et al., 1996): It is indeed mutations in the $23 \mathrm{~S}$ rRNA gene. Almost all resistant strains has a mutation: mutations A2143G and $\mathrm{A} 2144 \mathrm{G}$ are the most common. It has been shown that a mutation on one of the two copies of the 23S rRNA gene was sufficient to confer resistance. A strong association has been demonstrated between macrolide resistance, the absence of binding of the antibiotic to the ribosome and the presence of a mutation in the gene for $23 \mathrm{~S}$ rRNA position in 2143 or 2144 . It is now well accepted that these mutations are the cause of macrolide resistance in the vast majority of strains (Sevin et al., 2000). Oleastro et al. (2003) have developed a real-time PCR is a fast and accurate method to detect these mutations directly on biopsy specimens. In their work, the test has been successfully applied to reference strains, plasmids and reference biopsies $H$. pylori-negative. Biopsies of 200 patients who failed a first eradication attempt and for which the $H$. pylori strains was available were tested with the new method. This result was obtained in 199 cases, only one genotype was detected in 157 cases, two genotypes were detected in 41 cases and three genotypes were detected in one case. In four cases with discordant results, real-time PCR detected the resistant population so low that it could not be detected by the phenotypic method concentration, while in three cases other mutations could be involved. This assay accuracy at least as good as that of phenotypic tests and can be performed in $2 \mathrm{~h}$, which allows it to be used before the administration of therapy in the case of a first phase of H. pylori.

\section{CONCLUSION}

Two strains of $H$. pylori were isolated on blood agar (Hp1 and Hp3). Both strains showed phenotypic and biochemical characteristics of the species Helicobacter pylori. The real-time PCR was used to detect the presence of Helicobacter pylori in gastric biopsies. The real-time PCR method also allows to determine the sensitivity of $H$. pylori to clarithromycin.

\section{ACKNOWLEDGEMENTS}

This study was done at the bacteriological laboratory of the Cochin Hospital, Paris, for which I thank the Head of Department Prof. Poyart CLAIRE and Dr. Josette RAYMOND, for their invitation at the bacteriology laboratory of Cochin Hospital and have provided me with the necessary equipment to isolate and characterize strains of $H$. pylori. I also thank the entire team of the laboratory, including: Secretary Agnes ESSOMEE MOUNE and technician Nicolas CZARNA. The isolation and characterization of strains of $H$. pylori was performed with the aid of Dr. Mustapha DJEBAILLI, a gastroenterologist in Chlef, That I thank him very much.

\section{REFERENCES}

Allem, R., F.Z. Elkebir and H. Guetarni, 2007. Effect of the lactic acid bacteria on Helicobacter pylori in vitro. Med. Nut., 43: 121-127. DOI: $10.1051 / \mathrm{mnut} / 2007433121$

Bigard, M.A., 2004. Large trials that have changed (or not) my practice in the treatment of duodenal and ulceregastro-eradication Heliocbacterpylori. Med. Therapy, 10: 191-197.

Cassel-Beraud, A.M., M. Peghini, J.C. Mouden and P. Rajaonarison, 1996. Prevalence of infection Helicobacterpyloria Antananarivo, Madagascar. Bacteriology, 1441: 4-4. 
Debongnie, J.C., 1998. Helicobacter pylori: Diagnostic. ActaEndoscopica, 28: 179-203.

Elyse, P., 2002. The real-time PCR: Principles and Applications. Biol. Biotechnol., 1: 2-11.

Faik, M. and M. Raiss, 1998. Helicobacter pylori and gastric pathology. Med. Maghreb, 70: 37-40.

Kidd, M. and I.M. Modlin, 1998. A century of Helicobacter pylori. Digestion, 59: 1-15. DOI: 10.1159/000007461

Korwin, J.D. and A. Lozniewski, 2000. Helicobacter pylori: Basic concepts and perspectives. Elsevier,

Kuipers, E.J., 1999. Review article: Exploring the link between Helicobacter pylori and gastric cancer. Aliment Pharmacol. Ther., 13: 3-11. PMID: 10209681

Lamarque, D., C. Burucoa, A. Courillon-Mallet, J.D. De Korwin and J.C. Delchier et al., 2012. Revision des recommandations françaises sur la prise en charge de l'infection par Helicobacter pylori. Hepatol. Gastrol., 19: 475-502.

Malfertheiner, P., F. Megraud, C.A. O’Morain, J. Atherton and A.T. Axon et al., 2012. Management of helicobacter pylori infectiondthe maastricht iv/florence consensus report. Gut, 61: 646-664.

Megraud, F. and P. Lehours, 2007. Helicobacter pylori detection and antimicrobial susceptibility testing. Clin. Microbiol. Rev., 20: 280-322. DOI: 10.1128/CMR.00033-06

Monteiro, L., 1995. Helicobacter pylori: Factors bacterial pathogens. Hepatogastroenterology, 1: 227-230.

Oleastro, M., A. Menard, A. Santos, H. Lamouliatte and L. Monteiro et al., 2003. Real-time PCR assay for rapid and accurate detection of point mutations conferring resistance to clarithromycin in Helicobacter pylori. J. Clin. Microbiol., 41: 397402. PMID: 12517879
Peek, R.M. and M.J. Blaser, 2002. Helicobacter pylori and gastrointestinal tract adenocarcinomas. Nature Rev. Cancer, 2: 28-37. PMID: 11902583

Sevin, A.D., V. DeGruttola, M. Nijhuis, J.M. Schapiro and A.S. Foulkes et al., 2000. Methods for investigation of the relationship between drugsusceptibility phenotype and human immunodeficiency virus type 1 genotype with applications to AIDS clinical trials group 333. J. Infect. Dis., 182: 59-67. PMID: 10882582

SFM, 2010. REMIC: Referentiel en Microbiologie Medicale. 4th Edn., Societe Francaise De Microbiologie, ISBN-10: 2878050258, pp: 370.

Sobhani, I., T. Vallot and M. Mignon, 1995. Helicobacter pylori, une bactérie redécouverte: Son implication dans les maladies gastroduodénales $=$ Helicobacter pylori rediscovered: Implication in gastroduodenal disorders. Pressemedicale, 24: 67-79.

Thomas, G.R., J.E. Gibson, M.K. Darboe, A. Dale and L.T. Weaver, 1992. Isolation of Helicobacter pylori from human faeces. Lancet, 340: 1194-1195. PMID: 1359263

Versalovic, J., D. Shortridge, K. Kibler, M.V. Griffy and J. Beyer et al., 1996. Mutations in 23S rRNA are associated with clarithromycin resistance in Helicobacter pylori. Antimicrobial Agents Chemotheapy, 40: 477-480.

Warren, J.R. and J.B. Marshall, 1984. Unidentified curved bacilli in the stomach of patients with gastritis and peptic ulceration. Lancet, 323: 13111315. PMID: 6145023

Zine-Charafe, A., 2007. Gastric pathology and Helicobacter pylori infection. 